\title{
Serum Aspartic Acid as a Marker of Epilepsy
}

\author{
Gheyath AlGawwam ${ }^{1}$, Asaad Adil Mnaather ${ }^{2}$, Akram Al-Mahdawi ${ }^{3}$, Hayder A. Fawzi ${ }^{4} \&$ Laith G. Shareef $^{4}$ \\ ${ }^{1}$ Department of Neurology, College of Medicine, Baghdad University, Baghdad, Iraq \\ ${ }^{2}$ Department of Neurology, College of Medicine, Al-Muthanna University, Al-Muthanna, Iraq \\ ${ }^{3}$ Head of the Neurology Department, Baghdad Medical City, Baghdad, Iraq \\ ${ }^{4}$ Department of Clinical Pharmacy, Baghdad Medical City, Baghdad, Iraq \\ Correspondence: Hayder Adnan Fawzi, Department of Clinical Pharmacy, Baghdad Medical City, Baghdad, Iraq. \\ Tel: 964-772-262-7943. E-mail: hayder.adnan2010@gmail.com
}

Received: December 2, 2018 Accepted: December 28, 2018 Online Published: January 23, 2019

doi:10.5539/gjhs.v11n2p142 URL: https://doi.org/10.5539/gjhs.v11n2p142

\begin{abstract}
Objective: Determine the diagnostic validity of serum aspartic acid as a predictor of epilepsy.

Study Design and Methodology: This study enrolled 80 epileptic patients and 80 healthy people, and we measure serum level of aspartic acid by using high liquid performance chromatography.

Results: Mean serum aspartic acid was significantly higher in patients $(26.2 \pm 10.1) \mathrm{mg} \backslash \mathrm{dl}$ while in control was $(2.8 \pm 1.36) \mathrm{mg} \backslash \mathrm{dl}$, the result showed that aspartic acid is an excellent predictor area under the curve [AUC] $(95 \% \mathrm{CI})=0.988(0.97-1.0)$ with $96.3 \%$ sensitivity and $97.5 \%$ specificity for epileptic patients. Also, the result shows generalized seizure has significantly higher mean serum aspartic acid compared to partial type and GTC show significantly higher mean serum aspartic acid compared to myoclonus.
\end{abstract}

Conclusion: Aspartic acid serum level markedly elevated in epileptic patients groups in comparison to the healthy group, also shows a marked difference between generalized and partial epilepsy and show different levels between subtypes of epilepsy.

Keywords: aspartic acid, epilepsy, GTC, myoclonus

\section{Introduction}

Epilepsy is a disorder of the brain defined by any of the following conditions (at least two unprovoked seizures occurring greater than 24 hours apart, one unprovoked seizure and a probability of further seizures similar to the general recurrence risk (at least $60 \%$ ) after two unprovoked seizures, occurring over the next 10 years, and also involved the diagnosis of an epilepsy syndrome (Fisher et al., 2014). A seizure is a transient disturbance of cerebral function caused by an abnormal neuronal discharge while Epilepsy is a group of disorders characterized by recurrent Seizures (Holmes, 2012). Epilepsy can have both genetic and acquired causes, with the interaction of these factors in many cases. In about $60 \%$ of cases, the cause is unknown (National Clinical Guideline, 2012).

In many neurologic disorders, injury to neurons caused by overstimulation of receptors for an excitatory amino acid, including glutamic and aspartic acid (Choi, 1988). These neurologic conditions range from acute insults such as stroke, hypoglycemia, trauma, and epilepsy to chronic neurodegenerative states such as Huntington's disease, the acquired immunodeficiency syndrome (AIDS) dementia complex, Parkinson disease, amyotrophic lateral sclerosis, Canavan disease and perhaps Alzheimer's disease (Meldrum \& Garthwaite, 1990).

Aspartic acid present in high concentrations in the synaptic vesicles of axon terminals, depolarization of nerve endings with potassium ions evokes an immediate release of D-Aspartic acid in a $\mathrm{Ca}^{2+}$ dependent manner, specific receptors for D-Aspartic acid occur at the postsynaptic membrane; and stimulation of nerve endings with D-Asp triggers signal transduction by increasing the second messenger cAMPD, Aspartic acid plays an important role in the initial phases of central nervous system development in vertebrates (ICOSR, 2011, Obeid, Al-A'araji, Matti \& Fawzi, 2018). There is a significant increase in the contents of glutamate and aspartate was found beginning with the first 6 hours of the stroke onset and the degree and duration of such elevation correlated with severity of the stroke (Skvortsova et al., 1999) while there is decreased in plasma level of aspartic acid in Parkinson disease (Jimenez-Jimenez et al., 1996). 
Epilepsy is arising from aberrant electrical activity within the brain which result of biochemical processes at the cellular level promoting neuronal hyperexcitability and neuronal hypersynchrony (Meldrum, 1995), aspartic acid plays an important role in initiations, the spread of seizure activity and also associated with neuronal damage by its action on excitatory NMDA receptors. The density of NMDA receptors increased in epileptogenic regions. Patients with Mesial Temporal Lobe Epilepsy (MTLE) epilepsy have increased number of NMDA receptors in molecular layers (Mathern et al., 1999), and furthermore, the NMDA receptors antagonists are powerful antiepileptic drugs, also NMDA receptor increased in the over-activation of excitatory amino acid is implicated in pathophysiology of several clinical disorders like epilepsy, head trauma \& hypoxic-ischemic injury (Chen et al., 2005, Yahya, Kasim, AlGawwam \& Fawzi, 2018). In the current study, we aimed to measure the serum level of the excitatory amino acid (aspartic acid) in epileptic patients and compare it with healthy people, also to measure serum levels of aspartic acid in different types of epilepsy.

\section{Method}

\subsection{Study Design and Setting}

This study was a cross-sectional study, done from March-2015 to December -2015, consisted of eighty Iraqi epileptic patients. We collected patients randomly from those who registered in epilepsy clinic in Baghdad teaching hospital, Baghdad medical city complex. The patient's group ages ranged from $(10-40)$ years $\&$ control group ages ranged from (15-35) years.

\subsection{Subject Selection}

We included patients with a proven diagnosis of epilepsy and classified according to clinical semiology, EEG and imaging. Epileptic patients whose involve in this study had both generalized and partial, idiopathic types not suffered from structural lesions or infections, good compliance on anti-epileptic drugs (AEDs) and not have other medical illness. The Control group consists of eighty volunteers who are not complaining from epilepsy or other chronic medical illness. Also in this study, we classified epileptic patients into those responded to treatment or not, by having a seizure in the last 1st month or not, regardless of the type of AEDs they took.

\subsection{Laboratory Analysis}

Peripheral venous blood samples collected from patient \& control groups; centrifugations extracted the serum then transfer to clinical Lab to separate aspartic acid by chromatography procedure.

\subsection{Chromatography}

Chromatography is the method used to separate amino acids, nucleic acid and small molecules in complex mixtures from serum by using liquid chromatography technique separates molecules in a liquid mobile phase using solid stationary phase. In our research, we used column liquid chromatography techniques working in Private Lab. Chromatography based on the fact that different compounds can distribute themselves to varying extents between different phases, or separable portions of matter. One phase is the stationary phase, and the other is the mobile phase. The mobile phase flows over the stationary material and carries the sample to be separated along with it, the components of the sample interact with the stationary phase to different extents. Some components interact relatively strongly with the stationary phase and are therefore carried along more slowly by the mobile phase than are those that interact less strongly. The differing motilities of the components are the basis of the separation. Many chromatographic techniques used for research on proteins are forms of column chromatography, in which the material that makes up the stationary phase packed in a column. The sample is a small volume of concentrated solution that applied to the top of the column; the mobile phase, called the eluent, is passed through the column. The eluent dilutes the sample, and the separation process also increases the volume occupied by the sample.

\subsection{Statistical Analysis}

All continuous data follow a normal distribution, so mean and standard divination was used to represent the data. Continuous data analyzed using T-test when suitable to analyzed mean aspartic acid according to the test variable (two variables), ANOVA test used for continuous variables when there are three or more variables, data presented using the histogram. Chi-square test (Fisher exact test methods) used to analyze discrete variables (presented as a number, percentage) and data shown as a histogram. To identify whether serum aspartic acid was good predictor to differentiate between patients with epilepsy and normal control receiver operator curve (ROC) used, the outcome was area under the curve (AUC) [ $>0.9$ excellent test, $0.89-0.8$ good test, $0.79-0.7$ fair test, i.e., another test may be better and $<0.7$ poor test) and also cut off value of the aspartic acid identified with its respective sensitivity and specificity. P value was considered to be significant it is less than 0.05 Data were analyzed using SPSS version 
20 software package (Chicago, IL, USA)

\section{Results}

There was no significant difference in age and gender between epileptic patients and control as illustrated in table 1. Concerning epilepsy characteristic about 51 patients (63.75\%) were generalized type, and 29 patients (36.25\%) were partial type, generalized epilepsy consists of 41 patients with GTC $(51.25 \%)$ and 10 patients were myoclonus $(12.5 \%)$, while 20 of partial epilepsy had complex partial seizure, and 9 patients had secondary generalized seizure, 28 patients receive combination therapy $(35 \%)$ and 52 patients receive monotherapy $(65 \%)$. See the table (1). Mean serum aspartic acid was significantly higher in a patient with epilepsy $(26.2 \pm 10.1 \mathrm{mg} / \mathrm{dl})$ while for the healthy subject $(2.8 \pm 1.36 \mathrm{mg} / \mathrm{dl})$ p-value $<0.001$ see Table 1 .

To see whether serum aspartic acid is a good possible test to discriminate between patients and healthy subjects, we used receiver operator curve (ROC) to study the difference between epileptic patients and healthy subject with $96.3 \%$ sensitivity, $97.5 \%$ specificity at a serum level of $5.5 \mathrm{mg} / \mathrm{dl}$, as illustrated in Table 2 .

There no significant difference in mean serum aspartic acid in epileptic patient, when divided according to gender with p-value, was, Patient with generalized seizure $(29.42 \pm 8.98 \mathrm{mg} / \mathrm{dl})$ have significantly high serum aspartic acid than partial seizure $(20.54 \pm 9.67 \mathrm{mg} / \mathrm{dl}) \mathrm{p}$-value $<0.001$, GTC had the highest serum aspartic acid $(31.37 \pm$ $7.44 \mathrm{mg} / \mathrm{dl})$ which was significantly high versus both myoclonus $(21.4 \pm 10.65 \mathrm{mg} / \mathrm{dl}) \mathrm{p}$-value 0.005 and versus both type of partial seizure p-value $<0.001$, Monotherapy had mean serum aspartic acid $(27.83 \pm 9.92$ $\mathrm{mg} / \mathrm{dl})$ compared to combination therapy $(23.17 \pm 9.98 \mathrm{mg} / \mathrm{dl})$ however it was not statistically significant difference p-value 0.051 , as illustrated in Table 3 .

Aspartic acid is a fair test to predict the type of predicts myoclonus from GTC subtype of epilepsy, as illustrated in Table 4.

There no significant difference in mean serum aspartic acid in a patient with GTC when divided according to the type of regimen they used and the p-value was (0.069), there is no significant difference in mean serum aspartic acid in patient using sodium valproate \& carbamazepine which show the p-value (0.208), as illustrated in Figure 1.

Table 1. Assessment of demographic, clinical characteristics and aspartic acid between patients and control

\begin{tabular}{|c|c|c|c|}
\hline Variables & Patients & Control & p-value \\
\hline Number & 80 & 80 & - \\
\hline Age (years), mean $\pm \mathrm{SD}$ & $25.1 \pm 10.6$ & $27.1 \pm 8.3$ & 0.268 \\
\hline Gender & & & 0.560 \\
\hline Male, n (\%) & $43(53.8 \%)$ & $29(36.3 \%)$ & \\
\hline Female, n (\%) & $37(46.3 \%)$ & $41(63.8 \%)$ & \\
\hline \multicolumn{4}{|l|}{ Type of seizure } \\
\hline Generalized, n (\%) & $51(63.8 \%)$ & - & - \\
\hline Partial, n (\%) & $29(36.3 \%)$ & - & - \\
\hline \multicolumn{4}{|c|}{ A subtype of primary generalized epilepsy } \\
\hline GTC, n (\%) & $41(80.4 \%)$ & - & - \\
\hline Myoclonic, n (\%) & $10(19.6 \%)$ & - & - \\
\hline \multicolumn{4}{|l|}{ The subtype of partial epilepsy } \\
\hline Complex partial, n (\%) & $20(69.0 \%)$ & - & - \\
\hline Secondary generalized, n (\%) & $9(31.0 \%)$ & - & - \\
\hline \multicolumn{4}{|l|}{ Type of treatment } \\
\hline Combination, $\mathrm{n}(\%)$ & $28(47.5 \%)$ & - & - \\
\hline Monotherapy, n (\%) & $52(52.5 \%)$ & - & - \\
\hline Aspartic acid) mg/dl(, mean \pm SD & $26.2 \pm 10.1$ & $28 . \pm 1.4$ & $<0.001$ \\
\hline
\end{tabular}

SD: standard deviation, GTC: generalized tonic clonic. 
Table 2. Cut -off the value of Serum aspartic acid $(\mathrm{mg} / \mathrm{dl})$ that can differentiate between patient's and controls using ROC test

\begin{tabular}{lllll}
\hline AUC (95\%CI) & P value & Cut off value & Sensitivity & Specificity \\
\hline $0.988(0.97-1.0)$ & $<0.001$ & $>5.5$ & $96.3 \%$ & $97.5 \%$ \\
\hline
\end{tabular}

AUC: area under the curve, CI: confidence interval.

Table 3. serum aspartic acid (mg/dl) according to epilepsy type

\begin{tabular}{|c|c|c|c|}
\hline Variables & & Aspartic acid & p-value \\
\hline \multirow[t]{2}{*}{ Gender } & Male & $27.1 \pm 8.2$ & \multirow{2}{*}{0.103} \\
\hline & Female & $24.2 \pm 7.5$ & \\
\hline \multirow[t]{2}{*}{ Type of epilepsy } & Primary Generalized & $29.4 \pm 9.0$ & \multirow{2}{*}{$<0.001$} \\
\hline & Partial & $20.5 \pm 9.7$ & \\
\hline \multirow[t]{2}{*}{ A subtype of primary generalizes epilepsy } & GTC & $31.4 \pm 7.4$ & \multirow{2}{*}{$<0.001$} \\
\hline & Myoclonic & $21.4 \pm 10.7$ & \\
\hline \multirow[t]{2}{*}{ A subtype of partial epilepsy } & Secondary generalized & $22.3 \pm 8.4$ & \multirow{2}{*}{0.365} \\
\hline & Complex partial & $19.2 \pm 7.9$ & \\
\hline \multirow[t]{2}{*}{ Response to treatment } & No & $25.2 \pm 7.7$ & \multirow{2}{*}{0.110} \\
\hline & Yes & $28.1 \pm 8.3$ & \\
\hline \multirow[t]{2}{*}{ Type of treatment } & Combination & $23.2 \pm 10.0$ & \multirow{2}{*}{0.051} \\
\hline & Monotherapy & $27.8 \pm 9.9$ & \\
\hline
\end{tabular}

Data presented as mean \pm standard deviation.

GTC: generalized tonic clonic.

Table 4. ROC curve analysis of aspartic acid (mg/dl) for differentiation of patients subtypes of epilepsy (Myoclonus vs. GTC) and their cut off with their respective sensitivity and specificity

\begin{tabular}{lllll}
\hline AUC (95\%CI) & P value & Cut off value & Sensitivity & Specificity \\
\hline $0.790(0.621-0.960)$ & 0.005 & $>26$ & $75.6 \%$ & $70 \%$ \\
\hline
\end{tabular}

AUC: area under the curve, CI: confidence interval.
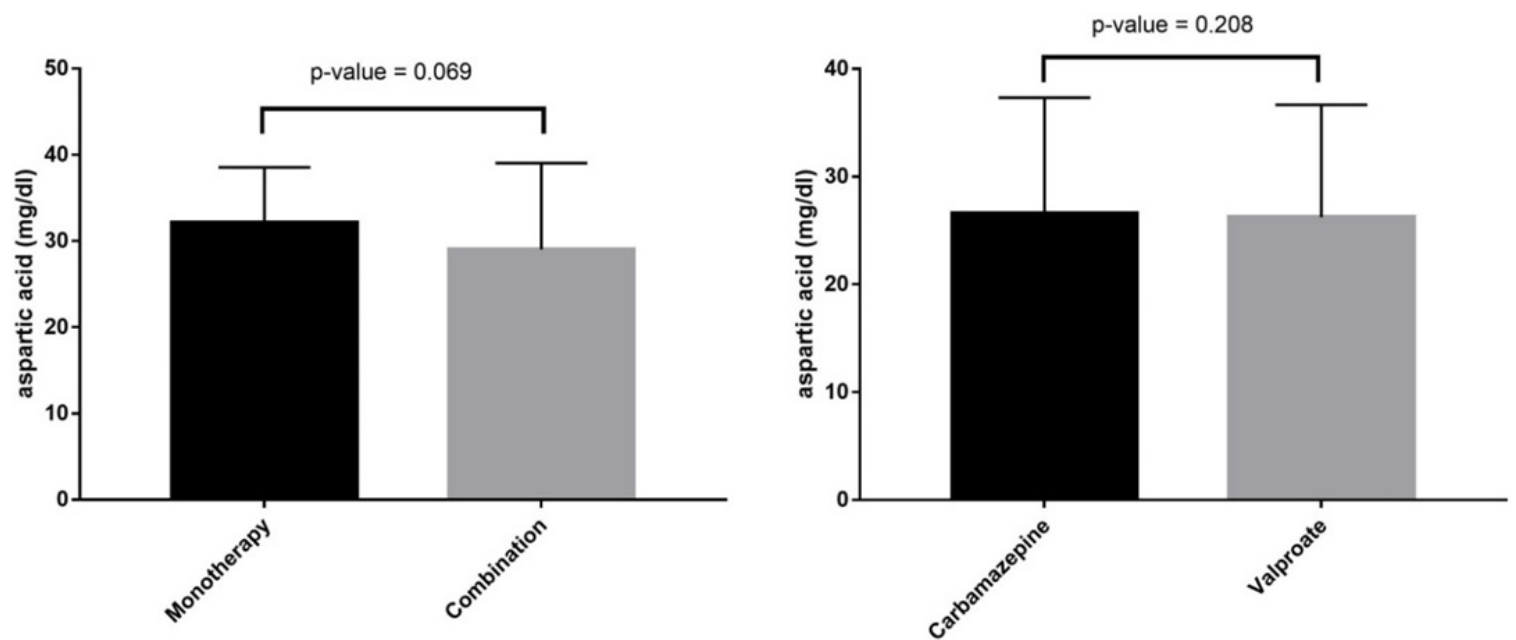

Figure 1. Comparison of serum aspartic acid between types of therapy in GTC (left), and between patients using either carbamazepine or valproate (right) 


\section{Discussion}

This study is examining the association between excitatory amino acid (aspartic acid) in epileptic patients. We estimate the excitatory amino acid (aspartic acid) for two groups of epileptic patient's generalized and partial epilepsy and their subtypes. The result shows that serum excitatory amino acid (aspartic acid) was a highly specific and sensitive marker to support the diagnosis of epilepsy in comparison to healthy persons according to ROC test, with $97.5 \%$ specificity and $96.3 \%$ sensitivity. Also mean serum aspartic acid (excitatory amino acid) level is elevated in both generalized and partial epilepsy $(29.42 \mathrm{mg} / \mathrm{dl}),(20.54 \mathrm{mg} / \mathrm{dl})$ respectively, compared to control group $(2.8 \mathrm{mg} / \mathrm{dl})$, regardless the subtypes. The result is in agreement with Janjua NA et al. as it shows increased excitatory amino acid in generalized and partial epilepsy in the Japanese population (Janjua et al., 1992).

In the current study, GTC seizure exhibit higher elevation of excitatory amino acid $(31.7 \pm 7.44) \mathrm{mg} / \mathrm{dl}$ in comparison with partial seizure $(20.54 \pm 9.67) \mathrm{mg} / \mathrm{dl}$ and this relatively consistent with study of Rainesalo et al (Rainesalo et al., 2004) which include (61 patients with 32 of them with GTC which showed mean level of excitatory amino acid is (28.7) and (27) patients with partial epilepsy showed mean level of excitatory amino acid was (18.7) and accordingly the GTC have higher serum excitatory amino acid than partial type (Rainesalo et al., 2004). In juvenile myoclonic epilepsy, our data showed increased in serum excitatory amino acid $(21.4 \pm 10.65)$ $\mathrm{mg} / \mathrm{dl}$ and this result is in agreement with study of Rainesalo et al that also include 27 patients with JME and showed that their serum excitatory amino acid level is higher than healthy controlled group (Rainesalo et al., 2004).

Also compared level of excitatory amino acid in epileptic patients regarding their response to treatment, we found that the level of excitatory amino acid is not significant between the none responders epileptic group (25.2 \pm 8.29$)$ $\mathrm{mg} / \mathrm{dl}$ and responders epileptic group (28.1 \pm 7.7$) \mathrm{mg} / \mathrm{dl}$ and these results is in agreement to Sariego-Jamardo et al (Sariego-Jamardo et al., 2015) which showed no significant difference between both groups, but Sariego-Jamardo et al. study in addition to AEDs used a ketogenic diet to manage 60 epileptic patients and measure amino acid for them, but this management not included in our study (Sariego-Jamardo et al., 2015).

There is no significant difference in mean serum excitatory amino acid in patients with GTC regarding the drugs used to control epilepsy and our result is in agreement with Monaco et al. who measured excitatory amino acid in 16epileptic patients with primary generalized epilepsy treated with sodium valproate and show no effect on excitatory amino acid (Monaco et al., 1994).

This study shows no difference in excitatory amino acid level between a patient taking carbamazepine or sodium valproate and these results are in agreement with study Rainesalo et al., which show that AEDs (carbamazepine, sodium valproate) had no marked effect of level of serum excitatory amino acid (Rainesalo et al., 2004). In Rainesalo et al. study which examined the efflux of L- aspartate and L- glutamate across the blood-brain barrier by using radioactive and platelets models, they show that the efflux of L-aspartate was seven times more than Lglutamate, this study shows the relationship between CSF and blood level of excitatory amino acid. So we speculate the change in serum aspartic acid are associated with the pathogenesis of seizure and may help in support diagnosis of epilepsy, which may be in part due to good correlation between blood and brain levels of this excitatory amino acid that plays a part in seizure induction (Rainesalo et al., 2004).

\section{Conclusion}

Serum aspartic acid is elevated in epileptic patients compared to a healthy person, which indicate that aspartic acid is a good test to support the diagnosis of epilepsy. The level of serum aspartic acid is variable between the types of epilepsy; this study showed that AEDs used had no major effect on the level of excitatory amino acid regardless of epilepsy type.

\section{Acknowledgements}

We the authors extend their thanks for the medical staff in Baghdad Medical city hospital and Baghdad college of Medicine to their help in completing this work.

\section{Competing Interests Statement}

The authors declare that there are no competing or potential conflicts of interest.

\section{References}

Chen, P. E., Geballe, M. T., Stansfeld, P. J., Johnston, A. R., Yuan, H., Jacob, A. L., Snyder, J. P., Traynelis, S. F., \& Wyllie, D. J. (2005). Structural features of the glutamate binding site in recombinant NR1/NR2A $\mathrm{N}$-methyl-D-aspartate receptors determined by site-directed mutagenesis and molecular modeling. $\mathrm{Mol}$ Pharmacol, 67, 1470-84. https://doi.org/10.1124/mol.104.008185 
Choi, D. W. (1988). Glutamate neurotoxicity and diseases of the nervous system. Neuron, 1, 623-34

Fisher, R. S., Acevedo, C., Arzimanoglou, A., Bogacz, A., Cross, J. H., Elger, C. E., ... Wiebe, S. (2014). ILAE official report: a practical clinical definition of epilepsy. Epilepsia, 55, 475-82. https://doi.org/10.1111/epi.12550

Holmes, M. D. (2012). The causes of epilepsy: common and uncommon causes in adults and children. Arch Neurol, 69, 1212-3. https://doi.org/10.1001/archneurol.2012.1266

ICOSR. (2011). Abstracts for the 13th International Congress on Schizophrenia Research (ICOSR). Schizophrenia Bulletin, 37, 1-327. https://doi.org/10.1093/schbul/sbq173

Janjua, N. A., Itano, T., Kugoh, T., Hosokawa, K., Nakano, M., Matsui, H., \& Hatase, O. (1992). Familial increase in plasma glutamic acid in epilepsy. Epilepsy Res, 11, 37-44. https://doi.org/10.1016/0920-1211(92)90019-P

Jimenez-Jimenez, F. J., Molina, J. A., Vargas, C., Gomez, P., Navarro, J. A., Benito-Leon, J., ... Arenas, J. (1996). Neurotransmitter amino acids in cerebrospinal fluid of patients with Parkinson's disease. J Neurol Sci, 141, 39-44.

Mathern, G. W., Mendoza, D., Lozada, A., Pretorius, J. K., Dehnes, Y., Danbolt, N. C., .. Adelson, P. D. (1999). Hippocampal GABA and glutamate transporter immunoreactivity in patients with temporal lobe epilepsy. Neurology, 52, 453-72.

Meldrum, B., \& Garthwaite, J. (1990). Excitatory amino acid neurotoxicity and neurodegenerative disease. Trends Pharmacol Sci, 11, 379-87.

Meldrum, B. S. (1995). Excitatory amino acid receptors and their role in epilepsy and cerebral ischemia. Ann N Y Acad Sci, 757, 492-505.

Monaco, F., Gianelli, M., Schiavella, M. P., Naldi, P., Cantello, R., Torta, R., Verze, L., \& Mutani, R. (1994). Plasma amino acid alterations in idiopathic generalized epilepsy: an investigation in probands and their first-degree relatives. Ital J Neurol Sci, 15, 137-44.

National Clinical Guideline, C. (2012). National Institute for Health and Clinical Excellence: Guidance. The Epilepsies: The Diagnosis and Management of the Epilepsies in Adults and Children in Primary and Secondary Care: Pharmacological Update of Clinical Guideline 20. London: Royal College of Physicians (UK), National Clinical Guideline Centre.

Obeid, S. F., Al-A'araji, S. B., Matti, B. F., \& Fawzi, H. A. (2018). Neopterin And Interferon-Gamma as Immune Response Markers In Beta-Thalassemia Major Patients. Asian Journal of Pharmaceutical and Clinical Research, 11, 192-4. http://dx.doi.org/10.22159/ajpcr.2018.v11i9.26661

Rainesalo, S., Keranen, T., Palmio, J., Peltola, J., Oja, S. S., \& Saransaari, P. (2004). Plasma and cerebrospinal fluid amino acids in epileptic patients. Neurochem Res, 29, 319-24.

Sariego-Jamardo, A., Garcia-Cazorla, A., Artuch, R., Castejon, E., Garcia-Arenas, D., Molero-Luis, M., ... Sanmarti, F. X. (2015). Efficacy of the Ketogenic Diet for the Treatment of Refractory Childhood Epilepsy: Cerebrospinal Fluid Neurotransmitters and Amino Acid Levels. Pediatr Neurol, 53, 422-6. https://doi.org/10.1016/j.pediatrneurol.2015.07.013

Skvortsova, V. I., Raevskii, K. S., Kovalenko, A. V., Kudrin, V. S., Malikova, L. A., Sokolov, M. A., ... \& Gusev, E. I. (1999). [Levels of neurotransmitter amino acids in the cerebrospinal fluid of patients with acute ischemic stroke]. Zh Nevrol Psikhiatr Im S S Korsakova, 99, 34-8.

Yahya, R. N., Kasim, A. A., Algawwam, G., \& Fawzi, H. A. (2018). Treatment satisfaction with disease-modifying therapy in relapsing-remitting multiple sclerosis in Iraq. International Journal of Research in Pharmaceutical Sciences, 9, 836-843. https://doi.org/10.26452/ijrps.v9i3.1578

\section{Copyrights}

Copyright for this article is retained by the author(s), with first publication rights granted to the journal.

This is an open-access article distributed under the terms and conditions of the Creative Commons Attribution license (http://creativecommons.org/licenses/by/4.0/). 